\title{
Chronic Viral Hepatitis Signifies the Association of Premixed Insulin Analogues with Liver Cancer Risks: A Nationwide Population-Based Study
}

\author{
Chien-Hsieh Chiang ${ }^{1,2,3}{ }^{(1)}$, Chia-Sheng Kuo ${ }^{4}$, Wan-Wan Lin ${ }^{2}$, Jun-Han Su ${ }^{5}$, Jin-De Chen ${ }^{6}$ and \\ Kuo-Chin Huang $1,7, *$ (i) \\ 1 Department of Family Medicine, National Taiwan University Hospital \& College of Medicine, Taipei 100, \\ Taiwan; jiansie@ntu.edu.tw \\ 2 Graduate Institute of Pharmacology, National Taiwan University College of Medicine, Taipei 100, Taiwan; \\ wwllaura1119@ntu.edu.tw \\ 3 Department of Community and Family Medicine, National Taiwan University Hospital Yunlin Branch, \\ Yunlin 640, Taiwan \\ 4 Department of Community and Family Medicine, National Taiwan University Hospital Bei-Hu Branch, \\ Taipei 108, Taiwan; omigodokuo@gmail.com \\ 5 Department of Molecular and Cellular Biology, Harvard University, Cambridge, MA 02138, USA; \\ junhansu@g.harvard.edu \\ 6 Division of Gastroenterology and Hepatology, Department of Internal Medicine, National Taiwan University \\ Hospital Bei-Hu Branch, Taipei 108, Taiwan; d900321@yahoo.com.tw \\ 7 Hepatitis Research Center, National Taiwan University Hospital, Taipei 100, Taiwan \\ * Correspondence: bretthuang@ntu.edu.tw; Tel.: +886-2-2312-3456 (ext. 66081); Fax: +886-2-2311-8674
}

Received: 4 April 2019; Accepted: 12 June 2019; Published: 13 June 2019

check for updates

\begin{abstract}
This study sought to determine whether chronic hepatitis B or C would modify the association between insulin analogues and hepatocellular carcinoma (HCC) risks. We conducted a nationwide nested case-control study for HCC cases and matched controls from 2003 to 2013 among newly diagnosed type 2 diabetes patients on any antidiabetic agents in Taiwan before and after exclusion of chronic viral hepatitis, respectively. A total of 5832 and 1237 HCC cases were identified before and after exclusion of chronic viral hepatitis, respectively. Incident HCC risks were positively associated with any use of premixed insulin analogues (adjusted odds ratio (OR), 1.27; 95\% CI 1.04 to 1.55) among total participants, especially among current users (adjusted OR, 1.45; 95\% CI 1.12 to 1.89 ). However, the association between HCC occurrence and premixed insulin analogues diminished among participants without chronic viral hepatitis (adjusted OR, 1.35; 95\% CI 0.92 to 1.98). We also observed a significant multiplicative interaction between chronic viral hepatitis and premixed insulin analogues on HCC risks $(P=0.010)$. Conclusions: Chronic viral hepatitis signifies the role of premixed insulin analogues in HCC oncogenesis. We recommend a closer liver surveillance among patients prescribed premixed insulin analogues with concomitant chronic viral hepatitis.
\end{abstract}

Keywords: hepatocellular carcinoma; chronic hepatitis B; chronic hepatitis C; population-based study; type 2 diabetes mellitus

\section{Introduction}

Hepatocellular carcinoma (HCC) ranks as a leading cause of cancer death, especially in Asia-Pacific regions [1]. Risk factors for HCC include not only chronic viral hepatitis and alcohol consumption [2-5], but also diabetes mellitus [6-14]. Existing systematic reviews have shown that diabetes mellitus was associated with increased risks of HCC and decreased disease-free survival [15,16]. A meta-analysis 
enrolling 21 cohort studies also demonstrated that type 2 diabetes increased the risk of HCC among patients with chronic liver disease, cirrhosis, chronic hepatitis $C$ virus infection, and chronic hepatitis $B$ virus infection [17]. Furthermore, investigators should clarify the independent role of antidiabetic agents in HCC development. There was research analyzing the database of National Health Insurance in Korea for associations of antidiabetic drugs with HCC [18]. The use of commonly prescribed insulin has been reported to increase the risk of HCC $[19,20]$. All insulin analogues are covered by health insurance in Taiwan and commonly used for glycemic control in general practice [21,22]. The safety concerns should neither be disregarded nor misunderstood. Nonetheless, most studies did not evaluate whether chronic viral hepatitis modifies the effects of insulin analogue on HCC. Therefore, we aimed to test the hypothesis that chronic viral hepatitis might modify the reported associations between exogenous insulin analogues and HCC risks in a nationwide population with newly diagnosed diabetes on any antidiabetic agents, before and after excluding chronic viral hepatitis.

\section{Materials and Methods}

\subsection{Data Source}

The National Health Insurance database in Taiwan includes complete outpatient visits, hospital stays, prescriptions, and disease and vital status for $99 \%$ of the country's population (approximately 23 million). The current analyses linked several large computerized claims datasets with the National Death Registry and the National Cancer Registry through the use of birth dates and civil identification numbers unique to each beneficiary. The datasets are protected under government laws and regulations, allowing no public access. The protocol had been reviewed by the Research Ethics Committee A of the National Taiwan University Hospital and complied with the categories of exemption from informed consent.

\subsection{Study Design and Population}

After critically designing the protocol based on our hypothesis and obtaining approval from the Minister of Health and Welfare, we retrospectively generated the study participants by computer linkage. We accessed the nationwide population for eligible participants, defined as newly diagnosed type 2 diabetes patients aged 30 to 90 years on any antidiabetic agents from the year of drug availability (2003 for premixed insulin and 2004 for insulin glargine or detemir) to 2013. We excluded participants if they did not have continuous insurance coverage 12 months before the index date; had a pre-existing diagnosis of diabetes or prescription of antidiabetic drugs within 12 months of study entry; or had a pre-existing diagnosis of type 1 diabetes or any cancer before the index date. Patients with a diagnosis of chronic hepatitis B or C infection or any relevant treatments were excluded from the corresponding analyses. Figure 1 illustrates flowcharts of the study participants before and after, excluding chronic viral hepatitis from 2003 to 2013. The flowcharts of the study participants from 2004 to 2013 are shown in Figure S1.

\subsection{Cases Ascertainment and Controls Selection}

Participants who had a first diagnosis of HCC with the ICD-9-CM code 155.0 were included as cases, confirmed by linking to Taiwan's National Cancer Registry and National Death Registry. For each case in the pre-specified cohorts described above, a risk-set sampling matched on age (within 5 years), gender, and follow-up duration was used to find four controls in the same cohort.

\subsection{Exposure Ascertainment and Covariate Adjustment}

The exposure of interest was use of insulin analogues before HCC occurrence. We collected information on drug types, dates of prescription, supply days, and total dosage dispensed from the outpatient pharmacy prescription database. Participants could receive a combination of these study insulin analogues or switch from one class to another. Exposure to these medications was treated as a 
time-dependent variable in the analysis. To investigate the influence of dose, we had calculated the cumulative use of each class of basal and premixed insulin analogues and then assigned the level of use based on tertiles of the cumulative dosage in a defined daily dose, which is the assumed average maintenance dose for an adult per day.

We incorporated inpatient and outpatient diagnostic files to ascertain the history of diabetes, chronic hepatitis B, chronic hepatitis C, liver cirrhosis, hypertension, hyperlipidemia, cardiovascular disease, cerebrovascular disease, peripheral vascular disease, chronic kidney disease, and depression based on ICD-9-CM codes. We also collected other information, such as age, gender, socio-economic status, and medical resource utilization during the study period.

\subsection{Statistical Analysis}

Demographic characteristics, medication use before cancer diagnosis, comorbidities, and resource utilization for cases and matched controls in study cohorts were separately presented. We only analyzed individuals with complete data. Conditional logistic regression before and after exclusion of chronic viral hepatitis was used to estimate the crude and adjusted odds ratios (ORs) and the $95 \%$ confidence intervals (CIs) for the association between use of insulin analogues and HCC occurrence, with non-use as the reference group. Potential covariates, including socioeconomic status, comorbidities at cancer diagnosis, any use of other medications, and medical resource utilization during the follow-up period, were added into the model. All study insulin analogues were incorporated into the models, while other variables were selected by a stepwise approach, i.e., $P<0.10$ for model entry and $P>0.05$ for removal. Discontinuation of insulin analogues use was defined by a lack of medication refill. We divided the person-time of study drug use into current, recent (from drug discontinuation to cancer diagnosis $<6$ months), and past use (from drug discontinuation to cancer diagnosis $\geq 6$ months). In the doseand duration-response analyses, we calculated the tertile-specific ORs for the cumulative dosage (low, intermediate, and high vs. non-use) and the cumulative duration of use (short, intermediate, and long vs. non-use). Additive and multiplicative interaction analyses between study analogues and chronic viral hepatitis on HCC risks were also performed. A two-sided $P<0.05$ was considered statistically significant. All statistical analyses were performed using SAS 9.4 (SAS Institute, Cary, NC, USA).

\section{Results}

\subsection{Patients' Characteristics and Univariate Analyses}

Considering the first year of availability for each insulin analogue (2003 or 2004) and the presence of chronic viral hepatitis, there were four sets of study participants in our study (Figure 1, Figure S1). In the univariate analysis from 2003 to 2013 before excluding participants with chronic viral hepatitis (5832 HCC cases), patients with incident HCC were more likely to use premixed insulin analogues, beta-blockers, and diuretics; and to have comorbid liver cirrhosis, chronic hepatitis $\mathrm{B}$, chronic hepatitis $\mathrm{C}$, heart failure, chronic kidney disease, and a higher Charlson index (Table S1). In the univariate analysis from 2003 to 2013 after excluding participants with chronic viral hepatitis (1237 HCC cases), HCC incidence was still positively related to any use of premixed insulin analogues (OR, 2.38; 95\% CI 1.77 to 3.20) (Table 1). Any use of antidiabetic drugs, statins, and fibrates remained inversely associated with risk of HCC occurrence whether before or after excluding chronic viral hepatitis. 


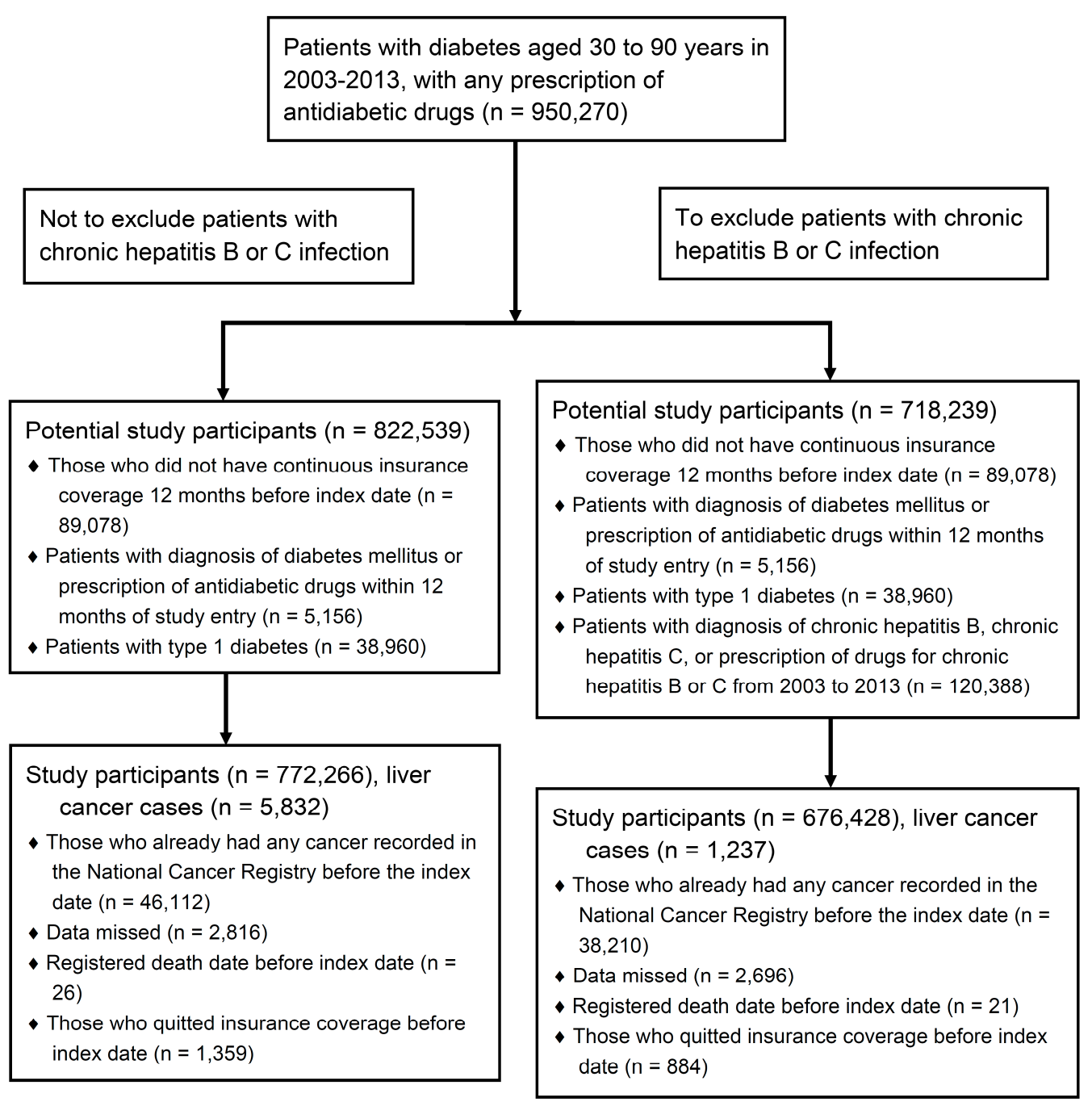

Figure 1. Study flowchart from 2003 to 2013 before and after exclusion of patients with chronic viral hepatitis.

Table 1. Hepatocellular carcinoma cases and matched controls among newly diagnosed type 2 diabetes patients without chronic viral hepatitis prescribed any antidiabetic agents.

\begin{tabular}{cccc}
\hline Factors & $\begin{array}{c}\text { Cases } \\
\mathbf{( N = 1 2 3 7 )}\end{array}$ & $\begin{array}{c}\text { Controls } \\
\mathbf{( N = 4 9 4 8 )}\end{array}$ & Crude OR (95\% CI) \\
\hline Age & $64.8(11.5)$ & $64.5(11.5)$ & - \\
Male & $932(75.3)$ & $3728(75.3)$ & - \\
\hline Year of initiating antidiabetic agents & & & - \\
\hline 2003 & $201(16.3)$ & $804(16.3)$ & - \\
2004 & $179(14.5)$ & $716(14.5)$ & - \\
2005 & $182(14.7)$ & $728(14.7)$ & - \\
2006 & $130(10.5)$ & $520(10.5)$ & - \\
2007 & $155(12.5)$ & $620(12.5)$ & - \\
2008 & $115(9.3)$ & $460(9.3)$ & - \\
2009 & $103(8.3)$ & $412(8.3)$ & - \\
2010 & $84(6.8)$ & $336(6.8)$ & - \\
2011 & $51(4.1)$ & $204(4.1)$ & $128(2.6)$ \\
\hline 2012 & $32(2.6)$ & $20(0.4)$ & \\
\hline
\end{tabular}


Table 1. Cont.

\begin{tabular}{|c|c|c|c|}
\hline Factors & $\begin{array}{c}\text { Cases } \\
(\mathrm{N}=1237)\end{array}$ & $\begin{array}{l}\text { Controls } \\
(\mathrm{N}=4948)\end{array}$ & Crude OR $(95 \%$ CI $)$ \\
\hline \multicolumn{4}{|c|}{ Socioeconomic status (monthly income in NTD) } \\
\hline$\leq 17,280$ & $530(42.9)$ & $2253(45.5)$ & Reference \\
\hline $17,281 \sim 22,800$ & $483(39.1)$ & $1774(35.9)$ & $1.16(1.01-1.33)$ \\
\hline $22,801 \sim 28,800$ & $54(4.4)$ & $202(4.1)$ & $1.14(0.83-1.57)$ \\
\hline $28,801 \sim 36,300$ & $56(4.5)$ & $219(4.4)$ & $1.09(0.79-1.49)$ \\
\hline $36,301 \sim 45,800$ & $65(5.3)$ & $240(4.9)$ & $1.15(0.85-1.55)$ \\
\hline$>45,800$ & $49(4.0)$ & $260(5.3)$ & $0.80(0.58-1.11)$ \\
\hline \multicolumn{4}{|l|}{ Medication use before cancer diagnosis } \\
\hline Premixed insulin analogues & $73(5.9)$ & $127(2.6)$ & $2.38(1.77-3.20)$ \\
\hline Oral antidiabetic drugs & $1058(85.5)$ & $4464(90.2)$ & $0.63(0.52-0.76)$ \\
\hline ACEi/ARBs & $99(8.0)$ & $389(7.9)$ & $1.02(0.81-1.29)$ \\
\hline Beta-blockers & $155(12.5)$ & $435(8.8)$ & $1.50(1.23-1.83)$ \\
\hline Calcium channel blockers & $73(5.9)$ & $273(5.5)$ & $1.08(0.82-1.42)$ \\
\hline Diuretics & $85(6.9)$ & $151(3.1)$ & $2.40(1.82-3.17)$ \\
\hline Statins & $147(11.9)$ & 915 (18.5) & $0.58(0.48-0.70)$ \\
\hline Fibrates & $137(11.1)$ & $658(13.3)$ & $0.81(0.66-0.98)$ \\
\hline \multicolumn{4}{|l|}{ Comorbidities } \\
\hline Liver cirrhosis & $283(22.9)$ & $36(0.7)$ & $39.7(27.0-58.6)$ \\
\hline Hypertension & $551(44.5)$ & $1934(39.1)$ & $1.26(1.11-1.44)$ \\
\hline Hyperlipidemia & $140(11.3)$ & $837(16.9)$ & $0.63(0.52-0.76)$ \\
\hline Ischemic heart disease & $134(10.8)$ & $446(9.0)$ & $1.23(1.00-1.51)$ \\
\hline Myocardial infarction & $15(1.2)$ & $52(1.1)$ & $1.16(0.65-2.06)$ \\
\hline Heart failure & $73(5.9)$ & $153(3.1)$ & $2.01(1.50-2.69)$ \\
\hline Atrial fibrillation & $20(1.6)$ & $66(1.3)$ & $1.22(0.73-2.01)$ \\
\hline Cerebrovascular disease & $117(9.5)$ & $488(9.9)$ & $0.95(0.77-1.18)$ \\
\hline Stroke & $68(5.5)$ & $319(6.5)$ & $0.84(0.64-1.11)$ \\
\hline Peripheral vascular disease & $9(0.7)$ & $32(0.7)$ & $1.13(0.54-2.36)$ \\
\hline Chronic kidney disease & $60(4.9)$ & $103(2.1)$ & $2.41(1.74-3.34)$ \\
\hline Depression & $15(1.2)$ & $63(1.3)$ & $0.95(0.54-1.68)$ \\
\hline Charlson index & $2.6(2.6)$ & $1.0(1.3)$ & $1.56(1.50-1.63)$ \\
\hline \multicolumn{4}{|l|}{ Resource utilization } \\
\hline Number of A1C measurements & $4.8(5.9)$ & $4.8(6.4)$ & $1.00(0.99-1.01)$ \\
\hline Number of lipid measurements & $4.3(5.3)$ & $4.5(5.8)$ & $0.99(0.98-1.00)$ \\
\hline Number of outpatient visits & $88.2(95.9)$ & $78.6(86.2)$ & $1.00(1.00-1.00)$ \\
\hline Number of hospitalizations & $2.0(3.24)$ & $1.1(2.2)$ & $1.15(1.12-1.18)$ \\
\hline Length of hospital stay $>7$ days & $1.0(2.0)$ & $0.6(1.4)$ & $1.19(1.14-1.24)$ \\
\hline
\end{tabular}

In the univariate analysis from 2004 to 2013 before excluding participants with chronic viral hepatitis (4573 HCC cases), HCC patients were more likely to use insulin glargine and insulin detemir, beta-blockers, and diuretics; and to have comorbid liver cirrhosis, chronic hepatitis B, chronic hepatitis $\mathrm{C}$, heart failure, chronic kidney disease, and a higher Charlson index (Table S2). In the univariate analysis from 2004 to 2013 after excluding participants with chronic viral hepatitis (952 HCC cases), the risk of incident HCC was still positively associated with use of insulin glargine and insulin detemir (OR, 1.49; 95\% CI 1.06 to 2.10) (Table S3). Any use of oral antidiabetic drugs, statins, fibrates, and angiotensin-converting enzyme inhibitors or angiotensin II receptor blockers was associated with a reduced risk of HCC occurrence. 


\subsection{Multivariate Analysis}

In the multiple conditional logistic regression analysis from 2003 to 2013, incident HCC risks were independently positively associated with any use of premixed insulin analogues (adjusted OR, 1.27; $95 \%$ CI 1.04 to 1.55) before exclusion of patients with chronic viral hepatitis (Table 2). As compared to non-users, there existed positive associations of increased HCC occurrences among current users of premixed insulin analogues (adjusted OR, 1.45; 95\% CI 1.12 to 1.89 ), those with high cumulative dosages of premixed insulin analogues (adjusted OR, 1.62; 95\% CI 1.16 to 2.26), and those with long (adjusted OR, 1.80; 95\% CI 1.30 to 2.51) or short duration (adjusted OR, 1.41; 95\% CI 1.03 to 1.93 ) of premixed insulin analogues. Nonetheless, there were no more independent positive associations between the incident HCC risks and any use premixed insulin analogues (adjusted OR, 1.35; 95\% CI 0.92 to 1.98) after exclusion of patients with chronic viral hepatitis. Similarly, the multivariate analysis from 2003 to 2013 showed any use of all insulin analogues to be positively associated with HCC occurrence only before exclusion of chronic viral hepatitis (adjusted OR, 1.20; 95\% CI 1.03 to 1.40) (Table S4). In the multiple conditional logistic regression analysis from 2004 to 2013 (Table S5), HCC occurrence was not significantly associated with any use of insulin glargine or detemir, whether after excluding participants with chronic viral hepatitis (adjusted OR, $0.91 ; 95 \%$ CI 0.58 to 1.42 ) or before excluding participants with chronic viral hepatitis (adjusted OR, $1.04 ; 95 \%$ CI 0.84 to 1.30 ).

Table 2. Risk of hepatocellular carcinoma associated with premixed insulin analogues among newly diagnosed type 2 diabetes patients prescribed any antidiabetic agents before and after exclusion of patients with chronic viral hepatitis.

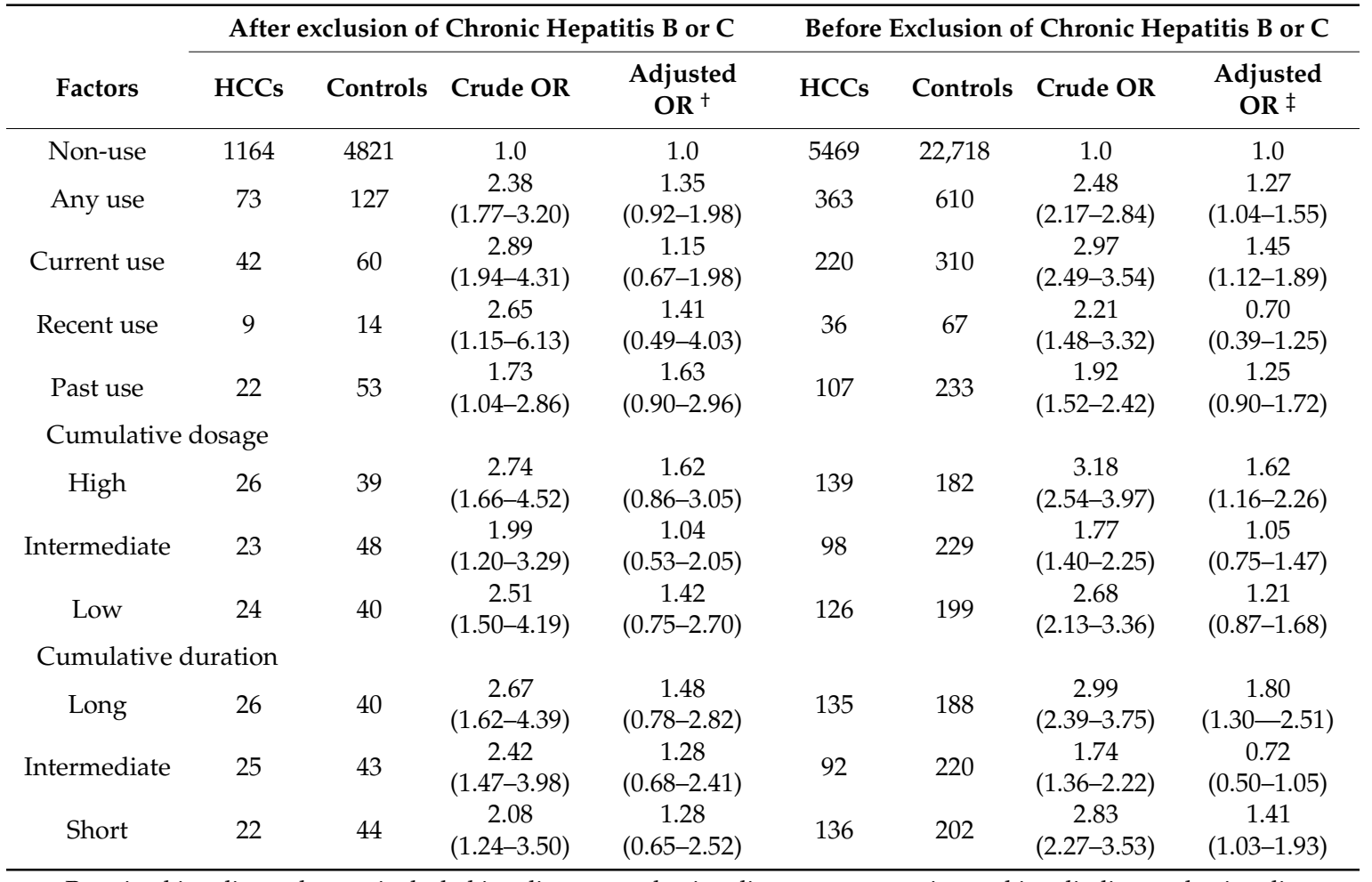

Premixed insulin analogues included insulin aspart plus insulin aspart protamine and insulin lispro plus insulin lispro protamine. ${ }^{\dagger}$ Adjusted for liver cirrhosis, hypertension, hyperlipidemia, cerebrovascular disease, Charlson score index, oral antidiabetic drugs, and statins. $¥$ Adjusted for socioeconomic status, chronic hepatitis B, chronic hepatitis $C$, liver cirrhosis, hyperlipidemia, heart failure, cerebrovascular disease, chronic kidney disease, Charlson score index, oral antidiabetic drugs, diuretics, statins, fibrates, aspirin, number of A1C measurements, number of lipid measurements, and number of outpatient visits. HCC, hepatocellular carcinoma cases. 


\subsection{Interaction Analyses}

There were significant multiplicative interactions between chronic viral hepatitis and premixed insulin analogues on risk of HCC after multiple adjustment $(P=0.010)$. When compared with participants who had neither chronic viral hepatitis nor any use of premixed insulin analogues, the sole presence of any use of premixed insulin analogues had a significantly higher adjusted OR of 1.51 for HCC occurrence. The addition of chronic viral hepatitis to any use of premixed insulin analogues further significantly increased the adjusted OR to 8.16 for HCC risk (Table 3). On the other hand, there was no significant multiplicative interaction between chronic viral hepatitis and insulin glargine or detemir on risk of HCC after multiple adjustment $(P=0.092)$ (Table S6).

Table 3. Interaction between premixed insulin analogues and chronic viral hepatitis on risk of hepatocellular carcinoma among newly diagnosed type 2 diabetes patients prescribed antidiabetic agents.

\begin{tabular}{cccccc}
\hline Premixed Insulin Analogs & Chronic Viral Hepatitis & HCCs & Controls & Crude OR & Adjusted OR $^{+}$ \\
\hline Non-use & Yes & 2998 & 1154 & $22.7(20.9-24.5)$ & $6.99(5.14-9.51)$ \\
Any use & No & 132 & 534 & $2.16(1.78-2.62)$ & $1.51(1.21-1.89)$ \\
Any use & Yes & 231 & 76 & $26.5(20.4-34.5)$ & $8.16(7.42-8.97)$ \\
\hline
\end{tabular}

Reference group: participants who had neither chronic viral hepatitis nor any use of premixed insulin analogues. $P$ value for multiplicative interaction equal to 0.010 ' $^{\dagger}$ Adjusted for socioeconomic status, liver cirrhosis, hyperlipidemia, heart failure, cerebrovascular disease, chronic kidney disease, Charlson score index, oral antidiabetic drugs, diuretics, statins, fibrates, aspirin, number of A1C measurements, number of lipid measurements, and number of outpatient visits. HCC, hepatocellular carcinoma cases.

\section{Discussion}

This population-based study explored the relationship between insulin analogues, chronic viral hepatitis, and HCC incidence among patients with newly-diagnosed type 2 diabetes who had been prescribed at least one kind of antidiabetic agent. We have demonstrated the presence of additive and multiplicative interactions between chronic viral hepatitis and any use of premixed insulin analogues on HCC occurrence. The significantly positive association between premixed insulin analogues and HCC occurrence diminished after exclusion of patients with chronic viral hepatitis.

This large-scale nested case-control study aimed to evaluate whether chronic viral hepatitis modifies the effects of antidiabetic drugs on HCC development. Almost no previous epidemiological studies had a sample size large enough to investigate the independent association of HCC risk with insulin analogues after patients with chronic viral hepatitis had been excluded. We utilized nationwide population-based cohorts in a HCC-endemic area to determine whether chronic viral hepatitis might signify the role of some insulin analogues in liver cancer oncogenesis.

We have to address some limitations in this research. First, it is limited in generalizability to patients other than the study population. Second, this nationwide database did not provide sufficient information about body mass index, serum lipid level, smoking habits, alcohol consumption, and out-of-pocket medication history. Obesity and low triglyceride levels were reported to be positively associated with an increased risk of primary liver cancer $[23,24]$. Nevertheless, these factors are seldom considered to affect the clinical indication, i.e., initiation of insulin analogues for the study participants. The National Health Insurance coverage of general population in Taiwan is $99.7 \%$ as of 2015 , and most of the study participants received health-insurance-covered medications for diabetes control, instead of more expensive out-of-pocket drugs [25]. Some may critique the underlying conditions of participants to be prescribed certain insulin analogues versus other anti-diabetic agents. Nonetheless, the present study did not show significant associations of any use of insulin analogues with HCC risks after exclusion of participants with chronic viral hepatitis. Actually, we intended to emphasize the intensified effect of chronic viral hepatitis on insulin analogues for HCC risks, rather than the independent role of each insulin analogue in HCC occurrence in the absence of chronic viral hepatitis. Finally, we chose a nested case-control design using a conditional logistic regression analysis rather than 
a survival analysis with the Cox model. However, the outcome of HCC in this large-scale nationwide nested case-control study was indeed very rare, especially in the setting without chronic viral hepatitis (Figure 1, Figure S1), which supports our original study design.

A growing number of studies have studied the association between insulin use and its HCC risk [26-30]. For example, a hospital-based case-control study indicated an insignificantly elevated risk of developing HCC associated with insulin use [30]. Some studies reported that insulin use was related to an increased risk of HCC development and mortality [26-28]. Nevertheless, these studies did not further investigate whether the increased risk persisted among each class of insulin analogues, neither did they clarify the influence of chronic viral hepatitis. Another case-control study observed increased risks for HCC in diabetic patients treated with insulin or sulfonylurea [29]. Although this study had considered hepatitis B, hepatitis C, and alcohol consumption to be confounding factors, multivariate analysis was not performed to elucidate the independent association between insulin use and the HCC risk.

Probable mechanisms linking insulin to increased HCC risks have been proposed [31-33]. Overexpression of insulin receptors might lead to HCC growth [31]. Hyperinsulinemia as a compensation for insulin resistance activates insulin receptor substrate-1, together with the downstream mitogen-activated protein kinase and phosphatidylinositol-3 kinase/Akt pathway, which could subsequently activate peroxisome proliferator activated receptor $\gamma$ [32]. The activation of peroxisome proliferator activated receptor $\gamma$ might then result in lipogenesis, adipogenesis, oxidative stress, and eventually HCC. Furthermore, hyperinsulinemia may also contribute to HCC development by inducing fibrogenesis of hepatic stellate cells, hepatocyte transformation, and angiogenesis of endothelial cells [33]. One recent study consistently demonstrated that the insulin-protein kinase and phosphatidylinositol-3 kinase/Akt-p70S6K pathways were involved in serum-enhanced cell proliferation during initial activation of hepatic stellate cells in rats [34].

Most HCC cases in Taiwan are attributable to chronic viral hepatitis [3]. Our results showed a significant interaction between chronic viral hepatitis and premixed insulin analogues on risks of HCC. Although there was neither a significant association between basal insulin analogues and HCC occurrence before exclusion of chronic viral hepatitis, nor a significant multiplicative interaction between chronic viral hepatitis and basal insulin analogues on risk of HCC after multiple adjustment, we consistently observed that chronic viral hepatitis signified the association of all insulin analogues with liver cancer risks after pooling together all kinds of insulin analogues for the multivariate analysis (Table S4). More experimental research should explore the interplay between chronic viral hepatitis and different insulin analogues in HCC oncogenesis. It is of note that the patient's physiological state on insulin therapy is not comparable to that of hyperinsulinemia. Actually, insulin therapy is suggested for type 2 diabetes patients who have a poor beta-cell reserve [35], which means decompensation and is not necessarily accompanied by hyperinsulinemia. In addition, the presence of hepatitis B virus may retain insulin receptors intracellularly at the endoplasmic reticulum and impede insulin receptor signaling, which could prevent compensatory liver regeneration and lead to liver disease progression [36]. Hepatitis $C$ virus might also induce insulin resistance through insulin receptor substrate-1 serine phosphorylation and upregulated gluconeogenesis [37]. Taken together, the exclusion of chronic viral hepatitis might weaken the effect of insulin resistance and hyperinsulinemia on HCC development. Whether exogenous insulin in type 2 diabetic treatment has a similar physiological effect as endogenous hyperinsulinemia in insulin resistance warrants further investigation.

\section{Conclusions}

This nationwide population-based nested case-control study has demonstrated an intensified effect of chronic viral hepatitis on premixed insulin analogues for HCC development among newly diagnosed type 2 diabetes patients ever prescribed any antidiabetic agents. We should consider both viral- and drug-related factors in liver cancer screening programs because chronic viral hepatitis signifies the association between certain insulin analogues and HCC oncogenesis. We recommend 
closer liver surveillance for diabetic patients currently prescribed premixed insulin analogues with concomitant chronic viral hepatitis in general practice.

Supplementary Materials: The following are available online at http://www.mdpi.com/1660-4601/16/12/2097/s1, Figure S1: Study flowchart from 2004 to 2013 before and after exclusion of patients with chronic viral hepatitis; Table S1: Hepatocellular carcinoma cases and matched controls among newly diagnosed type 2 diabetes patients prescribed any antidiabetic agents (from 2003 to 2013); Table S2: Hepatocellular carcinoma cases and matched controls among newly diagnosed type 2 diabetes patients prescribed any antidiabetic agents (from 2004 to 2013); Table S3: Hepatocellular carcinoma cases and matched controls among newly diagnosed type 2 diabetes patients without chronic viral hepatitis prescribed any antidiabetic agents (from 2004 to 2013); Table S4: Risk of hepatocellular carcinoma associated with all insulin analogues among newly diagnosed type 2 diabetes patients prescribed any antidiabetic agents before and after exclusion of patients with chronic viral hepatitis; Table S5: Risk of hepatocellular carcinoma associated with insulin glargine or detemir among newly diagnosed type 2 diabetes patients prescribed any antidiabetic agents before and after exclusion of patients with chronic viral hepatitis (from 2004 to 2013); Table S6: Interaction between insulin glargine or detemir and chronic viral hepatitis on risk of hepatocellular carcinoma among newly diagnosed type 2 diabetes patients prescribed any antidiabetic agents.

Author Contributions: Conceptualization, C.-H.C.; methodology, C.-H.C.; software, C.-H.C.; validation, C.-H.C. and C.-S.K.; formal analysis, C.-H.C., C.-S.K., J.-D.C., and K.-C.H.; investigation, C.-H.C., J.-D.C., and C.-S.K.; resources, C.-H.C.; data curation, C.-H.C. and C.-S.K.; writing-original draft preparation, C.-H.C., W.-W.L., J.-H.S., and C.-S.K.; writing-review and editing, C.-H.C., C.-S.K., W.-W.L., J.-H.S., J.-D.C., and K.-C.H.; visualization, C.-H.C.; supervision, C.-H.C. and K.-C.H.; project administration, C.-H.C.; funding acquisition, C.-H.C.

Funding: This research was funded by National Taiwan University Hospital Yunlin Branch, grant number NTUHYL104.A001.

Acknowledgments: We appreciate Ms. Ling-Ya Huang and Ms. Yuan-Ting Chang at the Health Data Research Centre, National Taiwan University for the contribution to the statistical analyses. The research team is also very grateful to all patients and physicians in this study.

Conflicts of Interest: The authors declare no conflicts of interest. The funders had no role in the design of the study; in the collection, analyses, or interpretation of data; in the writing of the manuscript, or in the decision to publish the results.

\section{References}

1. McGlynn, K.A.; London, W.T. The global epidemiology of hepatocellular carcinoma: Present and future. Clin. Liver Dis. 2011, 15, 223-243. [CrossRef] [PubMed]

2. El-Serag, H.B. Hepatocellular carcinoma. N. Engl. J. Med. 2011, 365, 1118-1127. [CrossRef]

3. Liao, S.F.; Yang, H.I.; Lee, M.H.; Chen, C.J.; Lee, W.C. Fifteen-year population attributable fractions and causal pies of risk factors for newly developed hepatocellular carcinomas in 11,801 men in Taiwan. PLoS ONE 2012, 7, e34779. [CrossRef] [PubMed]

4. Wen, C.P.; Lin, J.; Yang, Y.C.; Tsai, M.K.; Tsao, C.K.; Etzel, C.; Huang, M.; Hsu, C.Y.; Ye, Y.; Mishra, L.; et al. Hepatocellular carcinoma risk prediction model for the general population: the predictive power of transaminases. J. Natl. Cancer Inst. 2012, 104, 1599-1611. [CrossRef] [PubMed]

5. Aberg, F.; Helenius-Hietala, J.; Puukka, P.; Farkkila, M.; Jula, A. Interaction between alcohol consumption and metabolic syndrome in predicting severe liver disease in the general population. Hepatology 2018, 67, 2141-2149. [CrossRef]

6. Brower, V. Illuminating the diabetes-cancer link. J. Natl. Cancer Inst. 2012, 104, 1048-1050. [CrossRef]

7. Chen, C.L.; Yang, H.I.; Yang, W.S.; Liu, C.J.; Chen, P.J.; You, S.L.; Wang, L.Y.; Sun, C.A.; Lu, S.N.; Chen, D.S.; et al. Metabolic factors and risk of hepatocellular carcinoma by chronic hepatitis B/C infection: A follow-up study in Taiwan. Gastroenterology 2008, 135, 111-121. [CrossRef]

8. Davila, J.A.; Morgan, R.O.; Shaib, Y.; McGlynn, K.A.; El-Serag, H.B. Diabetes increases the risk of hepatocellular carcinoma in the United States: A population based case control study. Gut 2005, 54, 533-539. [CrossRef]

9. Inoue, M.; Kurahashi, N.; Iwasaki, M.; Tanaka, Y.; Mizokami, M.; Noda, M.; Tsugane, S. Metabolic factors and subsequent risk of hepatocellular carcinoma by hepatitis virus infection status: A large-scale population-based cohort study of Japanese men and women (JPHC Study Cohort II). Cancer Causes Control 2009, 20, 741-750. [CrossRef]

10. Lai, M.S.; Hsieh, M.S.; Chiu, Y.H.; Chen, T.H. Type 2 diabetes and hepatocellular carcinoma: A cohort study in high prevalence area of hepatitis virus infection. Hepatology 2006, 43, 1295-1302. [CrossRef] 
11. Chiang, C.H.; Lee, L.T.; Hung, S.H.; Lin, W.Y.; Hung, H.F.; Yang, W.S.; Sung, P.K.; Huang, K.C. Opposite association between diabetes, dyslipidemia, and hepatocellular carcinoma mortality in the middle-aged and elderly. Hepatology 2014, 59, 2207-2215. [CrossRef] [PubMed]

12. Elkrief, L.; Chouinard, P.; Bendersky, N.; Hajage, D.; Larroque, B.; Babany, G.; Kutala, B.; Francoz, C.; Boyer, N.; Moreau, R.; et al. Diabetes mellitus is an independent prognostic factor for major liver-related outcomes in patients with cirrhosis and chronic hepatitis C. Hepatology 2014, 60, 823-831. [CrossRef] [PubMed]

13. Fu, S.C.; Huang, Y.W.; Wang, T.C.; Hu, J.T.; Chen, D.S.; Yang, S.S. Increased risk of hepatocellular carcinoma in chronic hepatitis B patients with new onset diabetes: a nationwide cohort study. Aliment. Pharmacol. Ther. 2015, 41, 1200-1209. [CrossRef] [PubMed]

14. Chen, Y.; Wu, F.; Saito, E.; Lin, Y.; Song, M.; Luu, H.N.; Gupta, P.C.; Sawada, N.; Tamakoshi, A.; Shu, X.O.; et al. Association between type 2 diabetes and risk of cancer mortality: A pooled analysis of over 771,000 individuals in the Asia Cohort Consortium. Diabetologia 2017, 60, 1022-1032. [CrossRef]

15. Wang, P.; Kang, D.; Cao, W.; Wang, Y.; Liu, Z. Diabetes mellitus and risk of hepatocellular carcinoma: A systematic review and meta-analysis. Diabetes Metab. Res. Rev. 2012, 28, 109-122. [CrossRef] [PubMed]

16. Wang, Y.G.; Wang, P.; Wang, B.; Fu, Z.J.; Zhao, W.J.; Yan, S.L. Diabetes mellitus and poorer prognosis in hepatocellular carcinoma: A systematic review and meta-analysis. PloS ONE 2014, 9, e95485. [CrossRef]

17. Chen, J.; Han, Y.; Xu, C.; Xiao, T.; Wang, B. Effect of type 2 diabetes mellitus on the risk for hepatocellular carcinoma in chronic liver diseases: A meta-analysis of cohort studies. Eur. J. Cancer Prev. 2015, 24, 89-99. [CrossRef] [PubMed]

18. Seo, Y.S.; Kim, Y.J.; Kim, M.S.; Suh, K.S.; Kim, S.B.; Han, C.J.; Kim, Y.J.; Jang, W.I.; Kang, S.H.; Tchoe, H.J.; et al. Association of Metformin Use With Cancer-Specific Mortality in Hepatocellular Carcinoma After Curative Resection: A Nationwide Population-Based Study. Medicine 2016, 95, e3527. [CrossRef]

19. Singh, S.; Singh, P.P.; Roberts, L.R.; Sanchez, W. Chemopreventive strategies in hepatocellular carcinoma. Nat. Rev. Gastroenterol. Hepatol. 2014, 11, 45-54. [CrossRef]

20. Bowker, S.L.; Majumdar, S.R.; Veugelers, P.; Johnson, J.A. Increased cancer-related mortality for patients with type 2 diabetes who use sulfonylureas or insulin. Diabetes Care 2006, 29, 254-258. [CrossRef]

21. Diabetes Association Of The Republic Of China, T. Executive summary of the DAROC clinical practice guidelines for diabetes care- 2018. J. Formos. Med. Assoc. 2019. [CrossRef] [PubMed]

22. Taiwan National Health Insurance Drug List. Available online: https://reurl.cc/No409 (accessed on 7 June 2019).

23. Petrick, J.L.; Freedman, N.D.; Demuth, J.; Yang, B.; Van Den Eeden, S.K.; Engel, L.S.; McGlynn, K.A. Obesity, diabetes, serum glucose, and risk of primary liver cancer by birth cohort, race/ethnicity, and sex: Multiphasic health checkup study. Cancer epidemiol. 2016, 42, 140-146. [CrossRef] [PubMed]

24. Si, W.K.; Chung, J.W.; Cho, J.; Baeg, J.Y.; Jang, E.S.; Yoon, H.; Kim, J.; Shin, C.M.; Park, Y.S.; Hwang, J.H.; et al. Predictors of Increased Risk of Hepatocellular Carcinoma in Patients with Type 2 Diabetes. PloS ONE 2016, 11, e0158066. [CrossRef] [PubMed]

25. Universal Health Coverage in Taiwan. Available online: https://reurl.cc/OoGvD (accessed on 7 June 2019).

26. Tseng, C.H. Type 2 diabetes, smoking, insulin use, and mortality from hepatocellular carcinoma: A 12-year follow-up of a national cohort in Taiwan. Hepatol. Int. 2013, 7, 693-702. [CrossRef] [PubMed]

27. Miuma, S.; Ichikawa, T.; Taura, N.; Shibata, H.; Takeshita, S.; Akiyama, M.; Motoyoshi, Y.; Ozawa, E.; Fujimoto, M.; Kawashimo, H.; et al. The level of fasting serum insulin, but not adiponectin, is associated with the prognosis of early stage hepatocellular carcinoma. Oncol. Rep. 2009, 22, 1415-1424. [CrossRef] [PubMed]

28. Bosetti, C.; Franchi, M.; Nicotra, F.; Asciutto, R.; Merlino, L.; La Vecchia, C.; Corrao, G. Insulin and other antidiabetic drugs and hepatocellular carcinoma risk: A nested case-control study based on Italian healthcare utilization databases. Pharmacoepidemiol. Drug Saf. 2015, 24,771-778. [CrossRef]

29. Donadon, V.; Balbi, M.; Ghersetti, M.; Grazioli, S.; Perciaccante, A.; Della Valentina, G.; Gardenal, R.; Dal Mas, M.; Casarin, P.; Zanette, G.; et al. Antidiabetic therapy and increased risk of hepatocellular carcinoma in chronic liver disease. World J. Gastroenterol. 2009, 15, 2506-2511. [CrossRef] [PubMed]

30. Hassan, M.M.; Curley, S.A.; Li, D.H.; Kaseb, A.; Davila, M.; Abdalla, E.K.; Javle, M.; Moghazy, D.M.; Lozano, R.D.; Abbruzzese, J.L.; et al. Association of Diabetes Duration and Diabetes Treatment With the Risk of Hepatocellular Carcinoma. Cancer 2010, 116, 1938-1946. [CrossRef]

31. Spector, S.A.; Olson, E.T.; Gumbs, A.A.; Friess, H.; Buchler, M.W.; Seymour, N.E. Human insulin receptor and insulin signaling proteins in hepatic disease. J. Surg. Res. 1999, 83, 32-35. [CrossRef] 
32. Yu, J.; Shen, J.; Sun, T.T.; Zhang, X.; Wong, N. Obesity, insulin resistance, NASH and hepatocellular carcinoma. Semin. Cancer Biol. 2013, 23, 483-491. [CrossRef]

33. Chettouh, H.; Lequoy, M.; Fartoux, L.; Vigouroux, C.; Desbois-Mouthon, C. Hyperinsulinaemia and insulin signalling in the pathogenesis and the clinical course of hepatocellular carcinoma. Liver Int. 2015, 35, 2203-2217. [CrossRef] [PubMed]

34. Cai, C.X.; Buddha, H.; Castelino-Prabhu, S.; Zhang, Z.; Britton, R.S.; Bacon, B.R.; Neuschwander-Tetri, B.A. Activation of Insulin-PI3K/Akt-p70S6K Pathway in Hepatic Stellate Cells Contributes to Fibrosis in Nonalcoholic Steatohepatitis. Dig. Dis. Sci. 2017, 62, 968-978. [CrossRef] [PubMed]

35. American Diabetes Association. 9. Pharmacologic Approaches to Glycemic Treatment: Standards of Medical Care in Diabetes-2019. Diabetes Care 2019, 42, 90-102. [CrossRef] [PubMed]

36. Barthel, S.R.; Medvedev, R.; Heinrich, T.; Buchner, S.M.; Kettern, N.; Hildt, E. Hepatitis B virus inhibits insulin receptor signaling and impairs liver regeneration via intracellular retention of the insulin receptor. Cell. Mol. Life Sci. 2016, 73, 4121-4140. [CrossRef]

37. Parvaiz, F.; Manzoor, S.; Iqbal, J.; Sarkar-Dutta, M.; Imran, M.; Waris, G. Hepatitis C virus NS5A promotes insulin resistance through IRS-1 serine phosphorylation and increased gluconeogenesis. World J. Gastroenterol. 2015, 21, 12361-12369. [CrossRef] [PubMed]

(C) 2019 by the authors. Licensee MDPI, Basel, Switzerland. This article is an open access article distributed under the terms and conditions of the Creative Commons Attribution (CC BY) license (http://creativecommons.org/licenses/by/4.0/). 